
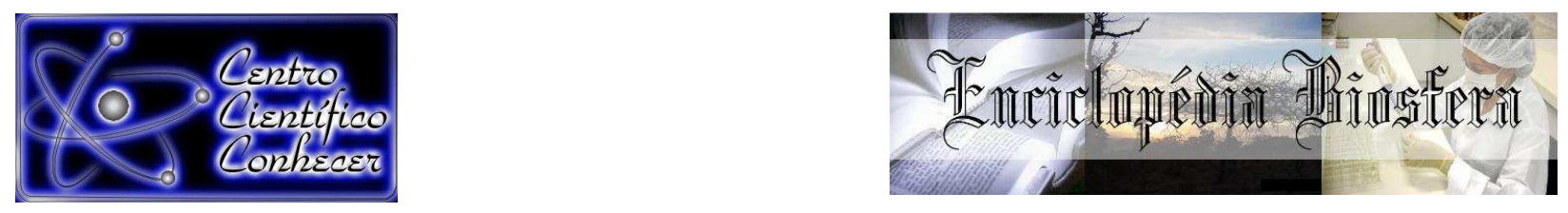

\title{
AVALIAÇÃO DO DESENVOLVIMENTO DE MUDAS DE JENIPAPO (Genipa americana L), INOCULADAS COM FUNGOS MICORRÍZICOS ARBUSCULARES
}

Andréa Hentz de Mello ${ }^{1}$; Domisley Sompré Sena ${ }^{2}$; Gustavo Ferreira de Oliveira ${ }^{3}$.

${ }^{1}$ Profa do Mestrado em Dinâmicas Territoriais e Sociedade na Amazônia, Universidade Federal do Sul e Sudeste do Pará. Marabá -Brasil. E-mail: andreahentz@unifesspa.edu.br;

${ }^{2}$ Engenheiro Agrônomo, Universidade Federal do Sul e Sudeste do Pará, MarabáBrasil;

${ }^{3}$ Mestre em Ciência do Solo, Universidade do Estado de Santa Catarina. LagesBrasil.

Recebido em: 08/04/2017 - Aprovado em: 10/06/2017 - Publicado em: 20/06/2017 DOI: 10.18677/EnciBio_2017A24

\begin{abstract}
RESUMO
O uso desordenado da floresta amazônica com monocultivos e exploração madeireira contribuem para 0 processo de desmatamento, causando consequências, como a baixa ocorrência natural de espécies nativas como o jenipapo (Genipa americana L.). O objetivo deste trabalho foi avaliar o desenvolvimento de mudas de jenipapo inoculadas com Gigaspora margarita e Glomus clarum. Este trabalho foi realizado em casa de vegetação/ Unifesspa em outubro, novembro, dezembro/2010 e janeiro/2011. Os esporos de FMAs utilizados nas mudas foram extraídos do banco de inoculo, da Embrapa Agrobiologia. A extração de esporos adotada foi o peneiramento úmido e centrifugação em água e em sacarose a $40 \%$. Foram preparados 20 recipientes com inóculos de G. margaritta e 20 de G. clarum. As sementes foram obtidas de uma planta em estágio de frutificação. Foram semeadas três sementes por cova em sacos plásticos com capacidade de $1 \mathrm{~kg}$ em substrato de um Argissolo Vermelho Amarelo. A inoculação foi efetuada no momento da semeadura. $O$ delineamento utilizado foi o inteiramente casualizado com três tratamentos, inoculação com 20 repetições cada, totalizando 60 mudas sendo um tratamento inoculado com G. margaritta e outro com G. clarum. Os parâmetros avaliativos foram: números de folhas, altura, diâmetro do colo e densidade micorrízica. As avaliações foram aos 30, 60, e 90 dias após a germinação. Os dados foram avaliados quanto a sua normalidade e processados com o software SISVAR $\AA$, submetidos a testes de média e variância. Verificou-se que os Fungos G. margarita promoveu maior desenvolvimento das mudas para os parâmetros avaliados.
\end{abstract}

PALAVRAS-CHAVE: espécie nativa, mudas de qualidade, organismo do solo. 


\title{
EVALUATION OF THE DEVELOPMENT OF JENIPAPO SEEDLINGS INOCULATED WITH ARBUSCULAR MYCORRHIZAL FUNGI
}

\begin{abstract}
The uncontrolled use of the Amazon forest with monocultures and logging contribute to the deforestation process, causing consequences, such as the low natural occurrence of native species such as genipapo (Genipa americana L.). The objective of this work was to evaluate the development of Jenipapo seedlings inoculated with Gigaspora margarita and Gloums clarum. This work was carried out in a greenhouse / UNIFESSEPA in October, November, December / 2010 and January / 2011. The FMA spores used in the seedlings were extracted from the inoculum bank of Embrapa Agrobiologia. The spore extraction was wet sieving and centrifugation in water and $40 \%$ sucrose. Twenty containers were prepared with G. margaritta and 20 G. clarum inocula. The seeds were obtained from a plant at the fruiting stage. Three seeds per seedlot were sown in plastic bags with a capacity of $1 \mathrm{~kg}$ on a substrate of a Red Yellow Argisol. The inoculation was carried out at the time of sowing. The design was a completely randomized design with three treatments, inoculation with 20 replicates each, totaling 60 seedlings being one treatment inoculated with $G$. margaritta and another with $G$. clarum. The evaluative parameters were: leaf numbers, height, neck diameter and mycorrhizal density. The evaluations were at 30 , 60 , and 90 days after germination. The data were evaluated for their normality and processed in the SISVAR $\AA$ application software, submitted to mean and variance tests. It was verified that $G$. margarita fungi promoted greater development of the seedlings for the evaluated parameters.
\end{abstract}

KEYWORDS: native species, quality seedlings, soil organism.

\section{INTRODUÇÃO}

Aproximadamente $75 \%$ dos solos da Amazônia, regionalmente conhecidos como terra firme, são classificados como Latossolo Amarelo e Argissolo VermelhoAmarelo. São solos profundos, bem drenados, em geral com boas propriedades físicas, mas de baixa fertilidade natural e acidez elevada (ALFAIA, 1997; MACEDO, 2012). O nutriente neles presente e, principalmente, na biomassa da floresta primária encontra-se em ciclo dinâmico, que é rompido pela conversão da floresta em sistemas agrícolas (ALFAIA, 1997).

O modelo convencional de exploração do solo na agricultura tem contribuído para o processo de degradação (GEBLER et al, 2012; SANTOS et al, 2012;). A perda de nutrientes é especialmente crítica para o fósforo, um elemento importante para as plantas e que se encontra em baixas reservas nos solos (COSTA, 2014). Nos sistemas naturais, a maior parte do fósforo mais rapidamente disponível no solo está retida na biomassa vegetal e, no processo de derruba e queima, esse nutriente é incorporado às cinzas, atuando como principal responsável pelos melhores índices de produtividade nos primeiros anos após a derrubada (WADT, 2003). Entretanto, a rápida diminuição da quantidade de fósforo assimilável no solo conduz invariavelmente a perda da capacidade produtiva das áreas cultivadas.

Nesse contexto, a busca de alternativas de manejo que racionalizem o uso dos recursos naturais da região é fundamental para o desenvolvimento econômico contínuo, socialmente justo e ambientalmente sustentável. A adoção de estratégias biológicas é uma alternativa a ser considerada no aperfeiçoamento de sistemas de manejo de nutrientes para a produção sustentada nos solos da Amazônia. Sob esse 
aspecto, as associações simbióticas micorrízicas arbusculares merecem especial atenção pelos benefícios apresentados em muitas espécies de plantas em condições de estresse, com destaque àquelas de natureza nutricional, especialmente de fósforo, como no caso de solos da Amazônia (MOREIRA \& SIQUEIRA 2002). Os fungos micorrízicos arbusculares (FMAs), em solos de baixa fertilidade natural, geralmente, promovem aumento no crescimento beneficiando a produção de massa seca nas plantas hospedeiras, entretanto a depender da espécie vegetal em questão os efeitos desses fungos podem ser diferenciados (GOMES JUNIOR, 2015).

Fungos micorrízicos arbusculares formam uma das associações mais comuns na natureza, a micorriza arbuscular, formada entre esses fungos e as raízes de aproximadamente $80 \%$ das plantas terrestres, com origem presumida há aproximadamente 460 milhões de anos (PEREIRA et al., 2012; INVAM, 2017).

No entanto é necessário um maior entendimento dos fatores ecológicos da comunidade de fungos (FMA), no sentido de manejá-los, com finalidade de se obter o máximo de benefícios desse tipo de simbiose. Espécies nativas da Floresta Amazônica são de grande importância na manutenção da biodiversidade deste bioma, bem como, são de grande importância na vida e cultura dos povos amazônidas (IPAM, 2015).

A espécie de Jenipapo (Genipa americana L.) é muito utilizada na vida cotidiana dos índios Gavião Kyikatêjê, tanto na utilização da tinta nas pinturas corporais, como na utilização no esporte, na corrida de toras. A comunidade indígena Kyikatejê, situada na BR 222, km 25, município de Bom Jesus do Tocantins-PA, atualmente vem necessitando atender uma grande demanda de tinta natural extraída do jenipapo. Diante disso, este trabalho teve como objetivo verificar o efeito de Fungos Micorrízicos Arbusculares (FMAs) no desenvolvimento de mudas de Genipa americana L., visando, maximizar o desenvolvimento das plantas destinadas a atender a insuficiência desses recursos na comunidade indígena Kyikatêjê.

\section{MATERIAL E MÉTODOS}

O trabalho foi realizado na casa de vegetação da faculdade de Ciências Agrárias de Marabá e no Laboratório de Agronomia da Universidade Federal do Sul Sudeste do Pará (FCAM/UNIFESSPA), Núcleo Nova Marabá, Campus II (lat 05을' $\mathrm{S}$, long 49 07' W, alt $84 \mathrm{~m}$ ), nos meses de outubro, novembro, dezembro de $2010 \mathrm{e}$ janeiro de 2011. O clima de Marabá/PA é caracterizado por temperatura média anual de $28,0 \stackrel{\circ}{\circ} \mathrm{C}$, com média das máximas de $32,7 \stackrel{\circ}{ } \mathrm{C}$ e média das mínimas de $23,3{ }^{\circ} \mathrm{C}$; precipitação total média anual de $1.925,7 \mathrm{~mm}$, sendo que $77 \%$ dessas precipitações ocorrem entre dezembro e abril, tendo março como o mês de maior precipitação pluvial (com média de $376,9 \mathrm{~mm}$ ), e 9,2\% das precipitações ocorrendo de junho a outubro, sendo agosto o de menor pluviosidade, com média de 11,8 mm (ALMEIDA, 2007).

Os esporos de FMAs utilizados no preparo das mudas foram extraídos do banco de inoculo (BIGM e BIGC), disponibilizados pela Embrapa Agrobiologia de Seropédica-RJ. Para a extração de esporos foi adotada a técnica de peneiramento úmido (GERDMANN \& NICOLSON, 1963), na qual o solo é dissolvido em água e após a decantação é submetido ao peneiramento, seguido da centrifugação em água e em sacarose a 40\% (JENKINS, 1964).

De cada amostra de solo do banco de inóculo BIGM e de BIGC foram 
retiradas $50 \mathrm{~g}$ para análise, dissolvidos em um litro de água e processado no liquidificador, aguardando-se por três minutos e depois de decantado o solo passou por duas peneiras acopladas, a superior correspondendo à malha de 0,210 micras e a inferior a 0,50 micras, repetindo o processo por três vezes. Depois desta etapa, o material retido na peneira foi colocado nos tubetes, complementados com água até preencher todo o tubete, em seguida foram levados para a centrífuga que foi programada a $2.000 \mathrm{rpm}$., durante três minutos. Realizada essa etapa 0 sobrenadante juntamente com o material suspenso dos tubetes foi descartado, porque o material de interesse (os esporos) estava retido na parte inferior do tubete. Em seguida, o tubete foi novamente preenchido desta vez com sacarose a $40 \%$ e levemente misturada ao material contido no mesmo, e foi levado novamente à centrifugação a 2.000 rpm por um minuto (BRUNDRETT et al., 1999).

Após o término da centrifugação o material peneirado na malha de 0,50 micras foi transferido para a placa de Petri para serem contados e separados os esporos. Depois da contagem, foram preparados 20 recipientes com inóculos de Gigaspora margaritta e 20 de Glomus clarum. Cada inóculo foi acondicionado em saquinhos plásticos, contendo $10 \mathrm{~mL}$ de água e 10 esporos puros de cada espécie.

As sementes foram obtidas de uma planta em estágio de frutificação no mês setembro de 2010, em uma propriedade na região de Marabá-PA. A quebra de dormência das sementes foi por imersão em água em temperatura ambiente por 48 horas (AZEVEDO \& GARCIA, 1999). Foram semeadas três sementes por cova em sacos plásticos com capacidade de um quilo em substrato de um Argissolo Vermelho Amarelo de barranco de áreas de exploração cerâmica com as seguintes características: Acides elevada, com baixa disponibilidade de bases $(\mathrm{K}, \mathrm{Ca}, \mathrm{Mg})$ e de macro nutrientes como Nitrogênio e Fósforo, além do Argissolo apresentar baixa capacidade de reter nutrientes assimiláveis à planta. A inoculação foi efetuada no momento da semeadura, realizado no dia 01 de outubro de 2010.

No preparo das mudas foi empregado o delineamento inteiramente casualizado (DIC) com três tratamentos de inoculação com 20 repetições cada, totalizando 60 mudas dispostas em bancadas da casa de vegetação, sendo um tratamento inoculado com Gigaspora margaritta e outro com Glomus clarum.

Os parâmetros avaliativos do desenvolvimento das plantas foram: números de folhas definitivas, altura, diâmetro do colo e densidade micorrízica. As primeiras germinações ocorreram dia 17 de outubro de 2010, 15 dias depois foram realizados os desbastes, deixando apenas uma planta por saco, com o objetivo de evitar competição entre elas. As avaliações foram aos 30, 60, e 90 dias após a germinação. Os dados foram avaliados quanto a sua normalidade e processados no software SISVAR ${ }^{\circledR}($ FURTADO, 2000), submetidos a testes de média e variância.

\section{RESULTADOS E DISCUSSÃO}

As primeiras germinações ocorreram 17 dias após a semeadura e aos 20 dias apresentaram as seguintes taxa de germinação: no tratamento Testemunha $25 \%$, no Tratamento Glomus clarum 40\% e no Tratamento Gigaspora margarita 60\%. Aos 30 dias as mudas inoculadas com $G$. margarita apresentaram $95 \%$ das germinações, $G$ clarum e Testemunha obtiveram $75 \%$ das germinações. Os parâmetros avaliados em função dos tratamentos foram altura, número de folhas, diâmetro do caule na superfície do solo (Tabela 1). 
TABELA 1. Parâmetros de crescimento analisados em função dos três tratamentos: altura, número de folhas, diâmetro do caule na superfície do solo.

\begin{tabular}{|c|c|c|c|}
\hline Tratamento & Altura (cm) & Número de folhas & Diâmetro (cm) \\
\hline Testemunha 30 & $3,28 \mathrm{c}$ & $1,00 \mathrm{~d}$ & $0,16 \mathrm{~b}$ \\
\hline Testemunha 60 & $7,30 \mathrm{c}$ & $3,50 \mathrm{c}$ & $0,23 \mathrm{~b}$ \\
\hline Testemunha 90 & $12,10 \mathrm{~b}$ & $3,65 \mathrm{c}$ & $0,35 \mathrm{a}$ \\
\hline Glomus clarum 30 & $3,29 c$ & $1,60 d$ & $0,14 b$ \\
\hline Glomus clarum 60 & $7,65 \mathrm{c}$ & $4,00 \mathrm{c}$ & $0,22 b$ \\
\hline Glomus clarum 90 & $12,17 b$ & $6,10 \mathrm{~b}$ & $0,35 \mathrm{a}$ \\
\hline Gigaspora margarita 30 & $4,06 \mathrm{c}$ & $1,50 \mathrm{~d}$ & $0,17 \mathrm{~b}$ \\
\hline Gigaspora margarita 60 & $7,30 \mathrm{c}$ & $4,10 \mathrm{c}$ & $0,24 \mathrm{~b}$ \\
\hline Gigaspora margarita 90 & $12,5 \mathrm{a}$ & $6,25 \mathrm{a}$ & $0,36 \mathrm{a}$ \\
\hline CV $(\%)^{*}$ & 33,22 & 37,28 & 30,83 \\
\hline
\end{tabular}

Foi observada que a altura das mudas inoculadas com o fungo $G$. margarita tiveram maior crescimento $(12,5 \mathrm{~cm})$, quando comparadas estatisticamente as mudas dos demais tratamentos. O número de folhas das mudas de jenipapo, seguiu o mesmo padrão de desenvolvimento, sendo que as mudas inoculadas com o fungo G.margaritta apresentaram em média 6,25 folhas quando comparadas com as testemunhas ( 3,15 folhas) e as inoculadas com G. clarum (6,10 folhas). Em relação ao diâmetro das mudas, não houve diferença significativa entre os tratamentos.

Com o decorrer do tempo houve crescimento natural das mudas e aumento gradativo nos parâmetros observados, o que comprova que quanto maior for o tempo de exposição do fungo com a raiz hospedeira, maior será os benefícios para a planta (MOREIRA \& SIQUEIRA, 2002). SOARES et al. (2012) avaliaram a associação micorrizica com diferentes fungos em mudas de jenipapeiro e verificaram que as mudas inoculadas com as espécies fúngicas apresentaram aumento significativo na altura, variando de $25,3 \%$ a $44,4 \%$, foi observada a influência positiva no diâmetro do caule das mudas colonizadas por G. clarum (58,1\%).

Diferenças significativas foram expressas aos 90 dias após a semeadura, na qual a inoculação com $G$. margarita apresentou o desenvolvimento máximo e favoreceu o crescimento das mudas quanto aos parâmetros avaliados: altura, número de folhas e diâmetro das mudas de Genipa americana L. A inoculação com G. clarum proporcionou um desenvolvimento inferior ao tratamento G. margarita quanto a número de folhas e altura, porém superior a Testemunha (Figura 1) e (Tabela 1). 


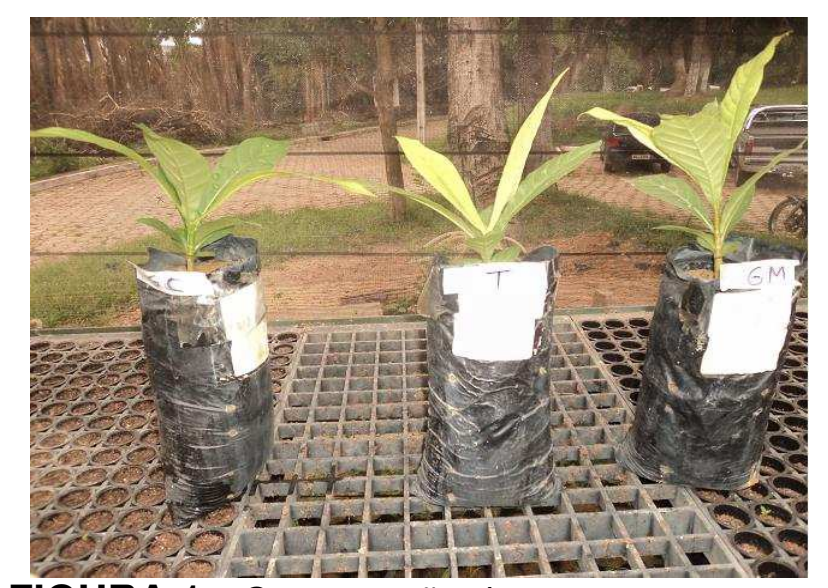

FIGURA 1 - Comparação dos tratamentos aos 90 dias: $G$. clarum (esquerda), Testemunha (centro) e G. margarita (direita).

Estes resultados corroboram com os de LIMA et al. (2015), que verificaram que na ausência de adubação fosfatada, as plantas de cedro inoculadas com o FMA Gigaspora margarita e todos os inóculos mistos, com exceção do tratamento Gigaspora margarita + Glomus clarum, apresentaram diâmetros dos caules, estatisticamente iguais às plantas testemunhas que continham 50 e $100 \mathrm{mg} \mathrm{dm}^{-3} \mathrm{de}$ $\mathrm{P}$ no solo.

$\mathrm{Na}$ densidade micorrizica, verificou-se que as mudas inoculadas com $G$. margarita, apresentam uma esporulação micorrízica $14 \%$ maior do que o tratamento com G. clarum e que o tratamento testemunha apresentou na repetição R20 quatro (4) esporos, podendo ser explicado por uma possível contaminação através do manejo frequente na casa de vegetação evidenciando, dessa forma, que $G$. margaritta promoveu maior eficiência na simbiose favorecendo o desenvolvimento de ambas as espécies (Tabela 2).

A elevada esporulação da $G$. margaritta, bem como a promoção do crescimento das mudas de jenipapo em detrimento ao $G$. clarum, pode estar relacionada com o que relatam MOREIRA \& SIQUEIRA (2002) e SOUZA et al., (2008), quando se referem a preferência de algumas espécies de plantas à certos fungos e não a sua especificidade.

TABELA 2- Avaliação da densidade micorrízica em $50 \mathrm{~mL}$ das amostras de solo dos tratamentos de inoculação.

\begin{tabular}{|c|c|c|c|c|c|c|}
\hline & G.margarita & Qtde. & G. clarum & Qtde. & Testemunha & Qtde. \\
\hline Repe & R 03 & 55 & R 01 & 21 & R 01 & 0 \\
\hline Repetição & R 08 & 51 & R 06 & 48 & R 06 & 0 \\
\hline Repetição & R 17 & 37 & R 17 & 32 & R 20 & 4 \\
\hline Média & & $46,5 a$ & & $33,5 b$ & & $4 c$ \\
\hline
\end{tabular}

Média seguida de mesma letra na linha não diferem estatisticamente a nível de 5\% pelo teste de Tukey.

Portanto, verificou-se que as mudas inoculadas com G. margarita, tiveram o desenvolvimento máximo aos 90 dias em casa de vegetação. Diante disto é possível ressaltar que mudas de qualidade inoculadas com Fungos Micorrízicos Arbusculares é uma alternativa agroecológica viável para maximizar a produção sustentável de mudas nativas como a de Genipa americana L. 


\section{CONCLUSÕES}

A espécie de Fungo Micorrízico Arbuscular (FMA) Gigaspora margarita favoreceu o desenvolvimento de Genipa americana L. para todos os parâmetros avaliados e para a esporulação micorrízica, principalmente aos noventa dias de avaliação.

A utilização de FMAs é uma alternativa viável para a produção de mudas da espécie nativa, para a comunidade indígena Kyikatêjê que poderá receber as mudas sadias e resistentes às condições ambientais adversas com grande potencialidade de desenvolvimento e produção no campo.

\section{REFERÊNCIAS}

ALFAIA, S. S. Destino de Adubos Nitrogenados Marcados com N em Amostras de dois Solos da Amazônia Central. Revista Brasileira de Ciências do Solo, 21:379385. Viçosa-MG, 1997. Disponível em: <http://dx.doi.org/10.1590/S010006831997000300005>. doi: 10.1590/S0100-06831997000300005.

ALMEIDA, M. Caracterização Agrometeorológica do Município de Marabá. Trabalho de Conclusão de Curso apresentado à Faculdade de Ciências Agrárias da Universidade Federal do Pará, Marabá, 2007. 118 p.

AZEVEDO, C. P.; GARCIA, L. C. Métodos Para Superar a Dormência de Sementes Florestais Tropicais. Embrapa Amazônia Ocidental (Instruções Técnicas). № 1 p. 1-4 ISSN 1517-2260 Manaus-AM. Setembro, 1999.

BRUNDRETT, M. C., JASPER, D. A., ASHWATH, N. Glomalean mycorrhizal fungi from tropical Australia II. The effect of nutrient levels and host species on the isolation of fungi. Mycorrhiza. v. 8, p. 315-321, 1999.

COSTA, A. R. Nutrição mineral em plantas vasculares. Edição: Escola de Ciências e Tecnologia da Universidade de Évora. Novembro de 2014. ISBN: 978989-97060-9-5 2014.

FURTADO, D, F. Sistemas de análise estatística para dados balanceados. Lavras:UFLA/DEX/SISVAR, , 2000. $145 \mathrm{p}$.

GEBLER, L.; BERTOL, I.; RAMOS, R. R.; LOUZADA, J. A. S.; MIQUELLUT, D. J. Fósforo reativo: arraste superficial sob chuvas simuladas para diferentes coberturas vegetais. Revista Brasileira de Engenharia Agrícola e Ambiental. v.16, n.1, p.99107, 2012. Disponível em: <http://dx.doi.org/10.1590/S1415-43662012000100013>. doi: 10.1590/S1415-43662012000100013.

GERDEMANN, J. W.; NICOLSON T. H. Spore of mycorrhizal Endogene species extracted from soil by wt-sieving and decanting. Transaction of British Mycological Society, v. 46, p 235-244, 1963.

GOMES JÚNIOR, G. A. Influência de fungos micorrizicos arbusculares no crescimento e nutrição de mudas de gravioleira (Annona muricata L.) Submetidas à adubação orgânica. 2015, 77p. Dissertação (Mestrado em Produção Vegetal) Programa de Pós-graduação em Produção Vegetal da Universidade 
Estadual de Santa Cruz. 2015.

INVAM - International culture colletion of vesicular arbuscular mycorrhizal fungi. Micorrihizal association in nature. Disponível em: <http:// invam.caf.wvu.edu/ Micorrihizal-association-in-nature.html. >. Acesso em: 8 de fev. de 2017

IPAM - Instituto de Pesquisas Ambiental da Amazônia. Estudos demonstram a importância dos indígenas na manutenção de florestas. Disponível em: <http:// www.ebc./noticias/meio-amabiente/2015/11/estudos-demonstram-a-importância-dosindígenas-na-manutenção-de-florestas.html>. Acesso em 26 de abril de 2015.

JENKINS, W. R. a rapid centrifufugal-floration technique for separating nematodes from soil. Plant Disease Report, v. 48, p. 692. p 71-99.1964.

LIMA, K.B.; NETTO, A.F.R.; MARTINS, M.A.; FREITAS, M.S.M. Crescimento, acúmulo de nutrientes e fenóis totais de mudas de cedro australiano (Toona ciliata) inoculadas com fungos micorrízicos. Ciência Florestal, v. 25, n. 4, p. 853-862, out.dez., 2015. Disponível em http://www.scielo.br/pdf/cflo/v25n4/0103-9954-cflo-25-0400853.pdf> doi 10.59021980509820583

MACEDO, A. G. S. Caracterização e variação temporal da solução do solo em Argissolo Amarelo com horizonte a moderado e a antrópico (terra preta de índio) no município de Iranduba - AM. 84 p 2012. Dissertação (Mestrado em Agronomia) Pós-Graduação em Agronomia Tropical da Universidade Federal do Amazonas. 2012

MOREIRA, F. M. S.; SIQUEIRA, J. O. Microbiologia e bioquímica do solo. Universidade Federal de Lavras, Lavras - MG, 2002. v.1. 625p.

PEREIRA, M. S. F.; ADDAD, L S. M.H.; AZZOLLID. M. S. B.; Kasuya, M. C. M. Micorriza arbuscular e a tolerância das plantas ao estresse. Revista Brasileira de Ciências do Solo, 36:1663-1679. Viçosa-MG, 2012. Disponível em: <http://dx.doi.org/10.1590/S0100-6832012000600001>. doi: 10.1590/S01006832012000600001.

SANTOS, J. O.; SANTOS, R. M. S.; ANDRADE, M. E. L.; SOUSA, D. F. M. A.; COELHO, D. C. Agricultura orgânica e a sustentabilidade. Revista Verde de Agroecologia e Desenvolvimento Sustentável. p. 59 - 65. Mossoró, Rio grande do Norte. 2012.

SOARES, A. C. F.; SOUSA, C. S.; GARRIDO, M. S.; LIMA, F. S. Fungos micorrízicos arbusculares no crescimento e nutrição de mudas de jenipapeiro. Revista Ciência Agronômica, v. 43, n. 1, p. 47-54, jan-mar, 2012. Disponível em: <http://dx.doi.org/10.1590/S1806-66902012000100006>. doi: 10.1590/S180666902012000100006.

SOUZA, F.A.; SILVA, I.C.L.; BERBARA, R.L.L. Fungos micorrízicos arbusculares: 
muito mais diversos do que se imaginava. In: MOREIRA, F.M.S.; SIQUEIRA, J.O. \& BRUSSSARD, L., eds. Biodiversidade do solo em ecossistemas brasileiros. Lavras, Universidade Federal de Lavras, 2008. p.483-536.

WADT, G. S. Práticas de Conservação do Solo e Áreas Degradadas. EMBRAPA Acre Documentos 90, 29p. Acre, 2003. 